\title{
Philosophy of Technology in the System of Modern Education*
}

\author{
Vladimir Tsvyk \\ Department of Ethics \\ RUDN University \\ Moscow, Russia \\ tsvyk_va@rudn.university.ru
}

\author{
Irina Tsvyk \\ Department of Philosophy \\ Moscow Aviation Institute \\ Moscow, Russia \\ tsvykirina@mail.ru
}

\begin{abstract}
The article is devoted to the role of philosophy of technology in the system of vocational education. Genesis, the development of the philosophy of technology, its structure and subject field are considered. It is noted that one of the main tasks of the philosophy of technology in modern society is the humanization of engineering and engineering education.
\end{abstract}

Keywords-technology; philosophy of technology; E. Kapp; P. Engelmeyer; humanization of education

\section{INTRODUCTION}

Studying the philosophy of technology at the present time is an important factor in ensuring the high quality of education, its adequacy to the conditions of life and professional activity of a person at the stage of unprecedented scale of scientific and technical development of society. The relevance of the relevant course in the system of Russian vocational education is due to the ever-increasing role of technology in the life of society, as well as the ambiguous assessment of such a role. On the one hand, technology itself is the greatest good of civilization and provides many other benefits. On the other hand, the development of technology brings many new realities in the life of society that are far from positive. In addition, with any attitude to technology, humanity is unlikely to be able to abandon it and its development, and technology becomes an integral accompanying element of the further crisis-free development of society. That is why technology has become an important object of philosophical reflection.

The field of philosophical interests of a person varies from one epoch to another, as the importance of one or another area of human activity increases; it becomes more independent, beginning to attract special attention. A person cannot do without a thorough analysis of what dominates his life. As an example to what has been said above, one can point to the philosophy of language. Even in antiquity, philosophers attached great importance to language, but not the most important. Only in the twentieth century, the philosophy of language begins to occupy a central place in

*This paper was financially supported by the Ministry of Education and Science of the Russian Federation on the program to improve the competitiveness of Peoples' Friendship University (RUDN University) among the world's leading research and education centers in the 2016-2020 (The Agreement number 02.A03.21.0008). philosophical knowledge. Something similar happened with the technique. Not immediately human civilization became technical, it happened somewhere by the twentieth century. It was at this time that the first works on the philosophy of technology appeared; they belonged to the German philosopher Ernst Kapp and Russian engineer P.K. Engelmeyer. Both thinkers were well aware that under the new conditions one should not confine oneself to a one-sided, narrow understanding of technology. As Engelmeyer noted, it is necessary to try to see in the future what the forms of interaction between technology and society should be. Understanding the technology in a broad perspective is impossible without philosophical understanding of a person's technical activity, its significance and prospects. How do philosophy and technology relate today-is it possible today to organically combine philosophical reflection over the world and its technical transformation, does technology have a philosophical meaning, and philosophy is technical? The answer to these questions is to give a study of the philosophy of technology in the system of vocational education.

\section{NATURE AND ESSENCE OF TECHNOLOGY}

The term "technology" is one of the oldest and widespread today. Until recently, it was used to refer to some vague activity or some combination of material entities. The content of the concept of technology has historically been transformed, reflecting the development of modes of production and means of labor. The initial meaning of the word art or skill refers to the activity itself, its qualitative level. Then the concept of technology reflects a certain way of manufacturing or processing. In handicraft production, individual craftsmanship is replaced by a combination of techniques and methods passed down from generation to generation. And, finally, the concept of "technology" is transferred to manufactured material objects. This occurs during the development of machine production, and the technique refers to various devices that serve production, as well as some products of such production. There are many definitions of technology: Greek techne meant craft, art, craftsmanship; a set of techniques and rules for doing something ...; activities aimed at meeting the needs of the individual, which leads to changes in the material world; a system of tools and machines; means of labor in a broad sense - all the material conditions necessary for the 
production process to be carried out in general; a system of actions through which a person seeks to achieve the realization of an out-of-nature program, that is, the realization of himself; the aggregate of material objects produced by society; the aggregate of material means of people's expedient activity; a system of artificial organs of human activity; a collection of mechanical robots to perform the work required by mankind.

In the Philosophical Encyclopedic Dictionary, the concept of "technology" is defined in two meanings: "... the totality of the means created for the implementation of the processes of production and servicing the non-productive needs of society". It also defines its main purpose: "complete or partial replacement of the production functions of a person with the aim of facilitating labor and increasing its productivity". The second meaning of the word is "a set of techniques and rules for doing something ..." [1].

The above definitions of technology can be grouped into three main groups. They can be represented as follows: technology as an artificial material system; technique as a means of activity; technique as certain modes of activity.

The first meaning (technique as an artificial material system) highlights one of the sides of the existence of technology, referring it to artificial material formations. But not all artificial material formations are techniques (for example, products of breeding activity that have a natural structure). Therefore, the essence of technology is not exhausted by such definitions, since they do not distinguish technology from other artificial material formations.

The second value is also insufficient. Technology is treated as a means of labor, a means of production, tools, etc. Sometimes the technique is immediately determined as a means, and as a tool. But this is not correct, since both concepts lie in the same plane of consideration and the means of labor are a broader concept in relation to the instruments of labor.

The third highlighted meaning is technology as certain modes of activity. But this essence is more in line with the notion of "technological process", which, in turn, is an element of technology [2].

So, the definitions of technology have been put forward quite a lot, mainly because the technique is a versatile and multifaceted phenomenon. Almost all definitions of technology are very useful, because they reflect either the level of scientific and theoretical analysis and knowledge of a given epoch, or certain material, scientific or social connections of technology, or its cultural context. However, in our opinion, any attempts to define technology cannot exhaustively reflect its essence and nature. The reason for this lies in the relative inexhaustibility of the very possibilities of technology and the abilities of man with the help of new cognitive means to reveal new sides, meaningful connections, possibilities and limitations of the technology itself.

The internal connection between various aspects of technology and technology itself with other spheres of knowledge and practical activity is so broad that it can only be comprehended on the basis of a well-developed methodological approach that is designed to develop a philosophy. The legitimacy of the philosophical study of technology in our day is conditioned not so much by the fact that technology, together with science, occupies a determining place both in the social, material and spiritual life of virtually all the peoples of the world and has actually changed the face of the globe, that precisely today, at a high level of technology development, some of its fundamental characteristics have become much clearer. It turned out, for example, that the development of technology forces us to reconsider some of the most important characteristics of science and its relationship with technology, in particular the conditionality of the development of science itself and scientific research by the successes and possibilities of technology. Technology often has a decisive influence on many important economic, environmental, social, scientific, political decisions. It is philosophy that is called upon to raise and understand the problem of the responsible use of technical systems in human activity.

Technology, as the most ancient kind of human activity, has always been and continues to serve as the basis of myth creation. Mythologizing technology has a long way of development from the myth of Prometheus, who taught people technical skills, about Daedalus and Icarus, who solved the technical problem of flying with wings, to modern myths about technogenic and technocratic civilization, the seizure of power by machines. The role of philosophy in understanding the true essence of technology and its significance in people's lives is great: it is philosophy that is the only means of transferring our attitude to technology from the sphere of myths, illusions to the ground of reality [3].

\section{THE INITIATION AND DEVELOPMENT OF PHILOSOPHY OF ENGINEERING}

A vivid evidence of the need for philosophical reflection on technology is the emergence in the last third of the twentieth century of the philosophy of technology as a new branch of philosophical knowledge. Ernst Kapp (1808-1896) was the first who made a bold move - in the title of his work he combined together the two previously incompatible concepts of "philosophy" and "technology." At the center of his book "The main directions of the philosophy of technology" is the principle of "organ projection", i.e. a person in all his creatures unconsciously reproduces his organs and knows himself from these artificial creatures [4]. According to P.K. Engelmeyer, this principle by Kapp does not stand up to criticism. "In fact, only a limited number of prehistoric tools, such as a hammer and an ax, can perhaps be viewed as projections of our limbs. But for the arrow already Kapp's principle becomes a question mark; and the wheel of the prehistoric cart no longer has a prototype in the animal body, and therefore the principle of designing organs to the machine is completely unacceptable. Kapp is forcibly, purely dialectically, extending his principle to the machine; but here his argument is extremely weak. He says, for example: "Although the general form of the steam engine is small, it does not even resemble the human body, but the 
individual organs are similar." What kind of them? Kapp wisely disclaims, for one mention of a cylinder with a piston, of a cranked shaft rotating in a bearing, denies the design of the organs as the principle of creating mechanisms"[5]. In his book "The Technical Outcome of the 19th Century" Engelmeyer speaks even more sharply, believing that onetenth of the book by E. Kapp is of some value, he calls it a historical unit, but the negative one [6]. Today, the attitude of technology philosophers to the ideas of E. Kapp is different. Especially in connection with the development of ideas of philosophical anthropology and many negative consequences associated with modern technology, which in Engelmeyer's time were not so obvious.

What is the essence of E. Kapp's main ideas? Fundamentals of his philosophy of technology are "anthropological criterion" and "principle of organ projection". Formulating his anthropological criterion, Ernst Kapp emphasizes: whatever the objects of thought, what thought finds as a result of all its searches, there is always a person. Therefore, the content of science in the research process is nothing more than a person returning to himself. Kapp believes that it was in the words of the ancient Greek thinker Protagoras - "Man is the measure of all things" - that the anthropological criterion was first formulated and the core of human knowledge and activity formed. It is due to the fact that man thinks himself in nature and from nature, and not above and outside it; the thinking of man becomes the coordination of his physiological organization with cosmic conditions.

Comprehending the concept of the external world of man, E. Kapp remarks that for him the word "nature" is not enough in the usual sense. To the external world, surrounding man, there are also many things that are his creation. Being artificial products, unlike natural products (nature supplies material for them), they form the content of the world of culture. E. Kapp holds a clear distinction between "natural" and "artificial": what is outside man consists of creatures of nature and man's creatures.

This outward appearance of man from the point of view of Kapp is a real continuation of his organism, transferring outward, an embodiment in matter, objectifying his ideas, i.e. part of yourself, something from your own "I". It is a reflection outside, as in a mirror, of the inner world of man. But the artificial world created by man becomes then a means of self-knowledge in the act of reversing the transfer from the external to the inner world. Including, thus, that a person learns the processes and laws of his unconscious life. In short, the "mechanism", unconsciously created by the organic pattern, serves itself to explain and understand the "organism". This is the essence of the principle of the organic projection of Ernst Kapp.

Kapp then proceeds from separate creations of technology to those powerful cultural means that do not fit into the notion of apparatus and have the character of systems. Such, for example, are the railways and telegraph, which covered the whole globe with the net. The first especially when connecting rail tracks and shipping lines into one, are a reflection of the system of blood vessels in the body. It is a communication artery through which the products necessary for the existence of mankind circulate. The second can be compared with the nervous system. Here, in Kapp's opinion, the organ projection celebrates its triumph: first, the construction, unconsciously proceeding according to the organic pattern, then the mutual recognition of the original and reflection (according to the law of analogy), and finally, like a spark, the consciousness of coincidence between the organ and the instrument flashes up to identity.

By the way, indirect confirmation of the principle of organ projection, understood, of course, not literally, is the development of modern microelectronics, which, having tried (unconsciously) all sorts of materials chose silicon as the most optimal material for integrated circuits. But it was his earlier evolution that "chose" the starting material of organic bodies. The layered synthesis of solid-state integrated structures, developed in modern technology for the production of microelectronic circuits, is also the most common in living and inanimate nature (for example, crystal growth, annual tree growth, skin formation). Here, the "organ projection" tends to display at least the lower levels of the biosynthetic structure. Moreover, the technological methods of layer-by-layer synthesis were effectively (and unconsciously) used in primitive technologies, starting with the Neolithic, for example, in the manufacture of jewelry, in printing, in the manufacture of ship armor [7].

The concept of E. Kapp's organ projection is the first attempt at a philosophical explication of the genesis of technology and its "anthropic" beginnings, a vivid example of the use of philosophical methodology in substantiating the essence of technology and technical systems. Attempts to answer the question what is technology and what its genesis is will still retain their heuristic role in the future and constitute an important section in the philosophy of technology.

In the focus of studying the philosophy of technology today, which is quite natural, there is the phenomenon and essence of technology. As a phenomenon, the technology appears in the form of machines and implements, but today also as technical structures and even the technical environment. The phenomenal characteristics of technology also include the knowledge used in technology, and various cultural "texts" in which technology is discussed, and the technical behavior of people. Unlike the phenomenal descriptions used in the philosophy of technology as an empirical material, understanding the essence of technology is the answer to such fundamental questions as: what is the nature of technology, how technology relates to other spheres of human activity - science, art, engineering, design, practical activity, when the technique arises and what stages it passes in its development, if the technology is really threatening our civilization, as many philosophers affirm, what the influence of technology on man and nature is, and what the prospects for development and changes in technology are.

It should be noted that these questions have interested the thinkers relatively recently. Although technology as the creation of tools and "technology" in the sense of the 
technological side of all activities (the technique of farming, the technique of making things, the technique of love, etc.) arose at the dawn of humanity, several tens of thousands of years ago, the phenomenon of technology in its modern sense was emphasized and realized only in the nineteenth century. Philosophical interpretation of technology refers to the second half and the end of the twentieth century.

Of course, in the history of philosophy there is a reflection about technology, but this reflection was, if I may say so, non-specific. For example, in ancient philosophy there is such a thing as "techne", but it means, in fact, not a technology, but any art of doing things, from the creation of paintings and sculptures to technical products, such as military vehicles. F. Bacon also discusses the possibility of manufacturing machines and technical products and the benefits that they can bring to people. But this discussion does not mean the phenomenon itself and the nature of technology, since it has not yet emerged in the consciousness of the New European man as an independent and, most importantly, problematic reality. Only in the twentieth century, technology is not only realized as an independent reality, but specific forms of reflection of this reality appear, first in the methodology of technical sciences, then, or almost simultaneously in philosophy.

\section{SUbJeCt OF PHILOSOPHY OF TECHNOLOGY: MODERN PROBLEMS}

The term "philosophy of technology" can be misleading. It seems that this is a section of philosophy in which technology is conceptualized and analyzed. But is it really so? Today philosophical knowledge (sections) such as "philosophy of art", "philosophy of science", "philosophy of nature", "philosophy of the spirit", "philosophy of law", "philosophy of culture" (by analogy - "philosophy of technology" or "philosophy of education"), are regarded more as a historical form of philosophical knowledge. Such a form of organization of philosophical knowledge seems outdated, gone into the past. But the names of the disciplines - "the philosophy of such and such area of study", both traditional and a number of modern ones, have been preserved. What do they mean in our time? First of all, if it's a philosophy, it's unconventional, modern. This is evidenced by the absence of a single philosophical system, the presence in addition to the philosophical forms of the reflexion of technology - historical, axiological, methodological, project, the existence of applied research and development in the philosophy of technology. So to say, the philosophical nature of reflections on the philosophy of technology is attached to such intentions of thinking that explain the idea and essence of technology, the understanding of the place of technology in culture and the social universe, the historical approach to the research of technology. Sometimes all these features of thinking are designated as philosophical transcendence, while claiming that it is transcendence that makes the philosophy of technology a philosophy [8].

Another point of view is that the philosophy of technology is not a philosophy, but rather an interdisciplinary field of knowledge, which is generally a broad reflection on technology. Two considerations reinforce this view. The first is that the philosophy of technology contains different forms of reflexion of technology, and therefore it differs far from classical philosophical traditions in terms of language. The second consideration is related to the nature of the tasks that the philosophy of technology solves. Reconstruction in the methodology of these problems shows that the philosophy of technology is focused on two main tasks. The first task - understanding of technology, understanding its nature and essence - was caused by a crisis of not mostly technology but of the entire modern "technogenic civilization." Gradually it becomes clear that the crises of our civilization - ecological, eschatological, anthropological (human degradation and spirituality), cultural crisis and others - are interrelated, and technology and, more broadly, the technical attitude to everything is one of the factors of this global unhappiness. This is why our civilization is increasingly called technogenic, bearing in mind the influence of technology on all its aspects and on man, as well as the deep technical origins of its development [9].

The second task is rather methodological in nature: it is a search in the philosophy of technology to solve the technology crisis, naturally, first, in the intellectual sphere of new ideas, knowledge, projects. If the philosophy of technology solves the two central tasks indicated here (understanding the nature and essence of technology, as well as finding ways and means to overcome the crisis created by technology and technogenic civilization), then its status is rather not a philosophy, but a private methodology, as well as interdisciplinary research and development. However, a number of modern philosophers, for example, V. Shvyrev, A Ogurtsov, argue that in addition to traditional problems and tasks, modern nonclassical philosophy deals with methodological and applied problems that are very similar to those that are discussed in the philosophy of technology. In this latter case, indeed, the philosophy of technology is a full-fledged nonclassical philosophical discipline.

The question of the status and nature of the philosophy of technology is associated with yet another problem, namely, whether to include in the philosophy of technology, so to speak, applied problems and issues. In fact, this is already happening: today, for example, the philosophy of technology includes such problems as the definition of the foundations of scientific and technical policy, the development of the methodology of scientific and technical and humanitariantechnical expertise, the methodology of scientific and technical forecasting, etc. However, at the dawn of the formation of this discipline, i.e. in the late 19th and early 20th centuries in the philosophy of technology, such applied, although quite broad problems were not included. The question here is: is it advisable to combine two such fields of nature and volume, which are so different in nature and scope, proper philosophical and methodological research of the problems, nature and essence of technology, as well as search in the intellectual sphere for ways to solve these problems, and not less significant and various in materials and methods applied problems; or it is more correct to separate applied problems and tasks from the philosophy of technology. 
The first solution of the problem seems to be more correct to us. In fact, philosophy fulfills not only ideological, but also a methodological function: it comprehends the basic issues of human existence and gives man "schemes of our orientation in reality." Orientation, in fact, means in a broad sense the orientation in the system of knowledge that we have developed about reality. As sources of knowledge, individual sciences have long replaced philosophy; the latter fulfills its orientation function as a partner in interdisciplinary dialogue. This is especially true of the philosophy of technology, which should use the knowledge developed by numerous scientific disciplines, in order to keep the multidimensionality of technology in the constant orientation framework.

From a more general point of view, productive ideas and considerations for a thorough understanding of technology can be obtained not only in the traditional philosophy of technology and in the modern theory of science and the social philosophy of technology, but also in certain philosophical and sociological concepts, in economic science, in the history of technology, as well as in recently formed generalizing directions of the technical science itself, especially in the science of construction, system engineering and in technical prognostics [10].

In our opinion, the main task of modern philosophy in the matter of substantiating technology is to turn into a complete and uniform model of describing the various elements of knowledge that are scattered and divorced from each other which have a philosophy and separate sciences with regard to technology. We have here in mind a common technology, some interdisciplinary generalizing system of utterances, the subject of which are the functional and structural principles of technical systems, as well as the human and social conditions for their emergence and application.

Like the general theory of technology, the general methods of researching technology must be constituted in a dialogue and in cooperation between philosophy and individual sciences. But if the technique of theoretical statements arising in the bosom of different disciplines should be integrated into one whole, then we need some theoretical integration potential, if we do not want all these different sources of knowledge in our hands to become an enormous pile of scattered individual knowledge. This integration potential can be provided by philosophy.

If we assume that the philosophy of technology still solves the two above-mentioned central tasks (understanding the nature and essence of technology, as well as finding ways and means to overcome the crisis created by technology and technogenic civilization), then its status is rather a philosophy supplemented by private methodology, as well as interdisciplinary research and development. In this case, the philosophy of technology is a full-fledged nonclassical philosophical discipline. Therefore, we include applied problems and problems in the philosophy of technology, such as the definition of the foundations of scientific and technical policy, the development of the methodology of scientific and technical and humanitarian-technical expertise, the methodology of scientific and technical forecasting, design, etc.

\section{CONCLUSION}

So, the usefulness of philosophy in the analysis of technical problems is twofold: first, classical fundamental philosophical problems in the technical age necessarily lead to certain conditions, possibilities and consequences of technology. Secondly, if an interdisciplinary generalized understanding of technology cannot be deduced from the analysis of particular sciences, certain concepts of economics, sociology, the history of technology and even technical sciences may prove very interesting. Therefore, the task of philosophy is to take care as an integrative, reflective science on the comprehensive orientation of scientific and technological culture. At the same time, it is not at all removed that philosophy can interpret itself as an exceptional, unique work of pure spirit. However, for all that, it can afford to act as a coordinating and critical partner in a dialogue with the individual sciences that operate in it.

We should not forget that philosophy is called upon to play a significant role in the prevention of very real dangers, which are warned against by critics of technocracy. It is about the possibility of suppressing the human personality and individual creativity in the conditions of the dominance of technology and the dehumanization of human relations [11]. Philosophy is able to substantiate and defend the most important position: not a man for technology, but technology for man and society. It is the cognitive and intellectual sphere of technology, where technical ideas, plans, projects and plans are formed, it is the source on which philosophy, with the help of its fundamental social, ethical, philosophical and philosophical and technical attitudes and interpretations can convince society of the unacceptability of the technocratic prospects for progress. Philosophy can most contribute to the development of reasonable alternatives to the concepts of technocracy.

The discussion of a wide range of technical problems has not only professional and philosophical significance and is interesting not only for specialists: philosophy is called upon to play a significant role in humanizing and enhancing the culture of technical thinking, development and strengthening of technological humanism [12].

One of the main tasks of the philosophy of technology now is the humanization of engineering and engineering education. As we can see, even the first philosophers of technology in their works of technology give an example of a broad, humanitarian view of technology. Nevertheless, today one of the main practical tasks of the philosophy of technology is the formation of a humanitarian concept of technology, and not only in the engineering environment, but also in society as a whole. And the solution of this problem is the obligatory teaching of the philosophy of technology, at least in higher technical educational institutions. This is one of the ways of humanizing science and technology through education. 


\section{REFERENCES}

[1] Philosophical Encyclopedic Dictionary. M. 2012.

[2] History and Philosophy of Science (Philosophy of Science) / E. Yu. Belskaya and others; Ed. Yu.V. Kryanev, L.E. Motorina, M., 2008, p. 57.

[3] Philosophy of technology in Germany, M., 1989, p. 5.

[4] E. Kapp, Grundlinien einer Philosophie der Technik; Zur Entstehungsgeschichte der Kultur aus neuen Gesichtpunkten, Duesseldorf, 1978.

[5] P.K. Engelmeyer, Philosophy of technology, M., 1912, issue. 2.

[6] P.K. Engelmeyer, The technical result of the XIX century, St. Petersburg, 1889, pp. 99-100.

[7] E. Kapp, Grundlinien einer Philosophie der Technik; Zur Entstehungsgeschichte der Kultur aus neuen Gesichtpunkten. Duesseldorf, 1978.

[8] I.V. Tsvyk, Professional ethics of the engineer // Professional ethics in modern society, M., 2011, pp. 88-101.

[9] V.S. Stepin, Perspectives of civilization: from the cult of power to dialogue and agreement // Ethical thought, M., 1992, p. 117.

[10] V.M. Rozin, Essence of technology // Law, worldview, philosophy, 2004, No. 1-2 (7-8).

[11] V.G. Gorokhov, Fundamentals of philosophy of engineering and technical sciences, M., 2004, pp. 78-80.

[12] V.A. Tsvyk, Moral Values of Professional Activity // Personality. Culture. Society, 2014, T. XVI, No. 1-2 (81-82), p. 265. 